\title{
TWIN PREGNANCY WITH ACARDIUS ANCEPS
}

Padma Shukla ${ }^{1}$, Neetu Ahirwar², Pooja Namdeo ${ }^{3}$

\section{HOW TO CITE THIS ARTICLE:}

Padma Shukla, Neetu Ahirwar, Pooja Namdeo. "Twin Pregnancy with Acardius Anceps". Journal of Evolution of Medical and Dental Sciences 2014; Vol. 3, Issue 09, March 3; Page: 2153-2155,

DOI: $10.14260 /$ jemds/2014/2119

ABSTRACT: Acardiac twin is an anomaly unique to monochorionic multiple pregnancies, characterized by formation of malformed fetus with an absent or rudimentary (nonfunctional) heart. Acardiac twinning, often results from abnormal placental vascular anastomoses. A 20 year old primigravida admitted to the department of Obstetrics and Gynecology S .S. Medical College, Rewa, on $26^{\text {th }}$ July 2012 at the gestation of 34 week with spontaneous monochorionic monoamniotic twin pregnancy and fetal acardius with oligohydramnios. Patient was taking her treatment from private Hospital; acardius was diagnosed at 27 week due to late booking. In view of oligohydramnios and hypoxic changes in color Doppler, elective LSCS was done on 28/7/13 at 34 week 2 day, after betnesol coverage. She delivered a live, healthy, female child with good APGAR score having apparently no congenital anomaly, with a birth weight of $2.3 \mathrm{~kg}$.The other twin was fetus acardius, of about900 gm. with head and face partially developed. Upper limb was rudimentary and lower limb was partially developed and malformed. External genitalia were developed as female. Placenta was monochorionic and monoamniotic, weighing500 gm. The umbilical cord of the normal twin was $20 \mathrm{~cm}$ with central attachment, while the other umbilical cord was $10 \mathrm{~cm}$ long with peripheral attachment.

KEYWORDS: Acardiac twin, Monochorionic multiple pregnancies, Twin to twin transfusion syndrome.

INTRODUCTION: Acardiac twin is an anomaly unique to monochorionic multiple pregnancies, characterized by formation of malformed fetus with an absent or rudimentary (nonfunctional) heart. Acardiac twinning, often results from abnormal placental vascular anastomoses. This leads to twin reversal arterial perfusion with complex pathophysiology .Occurring at an incidence of 1 in 34,600 deliveries or $1 \%$ of monozygotic twins ${ }^{1}$.

CASE REPORT: A 20 year old primigravida admitted to the department of Obstetrics and Gynecology S. S. Medical College, Rewa, on $26^{\text {th }}$ July 2012 at the gestation of 34 week with spontaneous monochorionic monoamniotic twin pregnancy and fetal acardius with oligohydramnios. Patient was taking her treatment from private Hospital; acardius was diagnosed at 27 week due to late booking. In view of oligohydramnios and hypoxic changes in color Doppler, elective LSCS was done on 28/7/13 at 34 week 2 day, after betnesol coverage. She delivered a live, healthy, female child with good APGAR score having apparently no congenital anomaly, with a birth weight of $2.3 \mathrm{~kg}$.The other twin was fetus acardius, of about $900 \mathrm{gm}$. with head and face partially developed. Upper limb was rudimentary and lower limb was partially developed and malformed. External genitalia were developed as female. Placenta was monochorionic and monoamniotic, weighing $500 \mathrm{gm}$. The umbilical cord of the normal twin was $20 \mathrm{~cm}$ with central attachment, while the other umbilical cord was $10 \mathrm{~cm}$ long with peripheral attachment. 
DISCUSSION: Acardia represents one of the most severe and rarest congenital anomaly. Based on the degree of cephalic and truncal maldevelopment, four types are recognized:

1. Acardius anceps -head and face partially developed.

2. Acardius acephalus-no cephalic structures

3. Acardius acormus -there is head, but no body; rarest type.

4. Acardius amorphous -formless blob containing all types of tissue, but no recognizable organs.

Two- third of acardiac fetuses are acardiac acephalic, which is the most common variety, and they are female ${ }^{2}$. This case was Acardius anceps with female genitalia.

Several theories had been postulated to explain TRAP sequence. The most accepted theory is that, artery-to-artery anastomosis between monochorionic twins in the first trimester is the fundamental event in the development of TRAP sequence. There is preferential perfusion of the parasitic twin's lower body with low pressure hypoxemic blood coming from the normal donor twin. This resulting in a living thing which does not have a heart, together with varying degrees of upper body regression in the recipient twin. The burden of providing circulation for two fetuses can result in cardiac hypertrophy, congestive failure, and hydrops fetalis in donor twin. This was not the case in this patient, who delivered healthy child with good Apgar score.

The diagnosis can be reliably made on ultrasound scan in first trimester. But the diagnosis is not always simple. The most frequent confusion is with anencephaly or with fetal demise of one twin. It is easy to erroneously diagnose fetal death in these cases because of the absence of cardiac motion and movement in the acardiac twin. In this case diagnosis was made by USG with Doppler study but the diagnosis was quite late at 27 week due to late booking of the patient. MRI maybe useful as an adjunct in already identified cases to assess the presence of retrograde blood flow in the acardiac fetus and umbilical artery ${ }^{3}$. Early diagnosis reduces the risk of complication, as the perinatal mortality rate is reported to be 50-70\% for donor twin.

Management of acardiac twin is complex. Potential treatment include administration of cardio tonics to the mother or the fetus, serial amniocenteses, selective removal of the acardiac twin, or insertion of a thrombogenic coil in the umbilical artery of the acardiac twin. Another method is the interruption of the A-A anastomosis between the donor and the acardiac twin. This can be achieved by endoscopic laser photocoagulation when pregnancy is less than 24 week or by endoscopic or ultrasound guided ligature of the umbilical cord of the acardiac twin when the gestational age is more advanced.

\section{REFERENCES:}

1. Kim Tae Jin, Kim Chong Jai, Park Sung Hye et al. Holoacardius ahaemisomus Acephalus. A Case Report. Kor J Path.1989:23:487-9.

2. Dhall U, Kayalvizi I, Merg S. Acardius Acephalus. Monster-A Case Report. J Anat Soc India .2005;54:26-8

3. Hata N, Wada T, Kashima K, Okada Y, Unno N, Kitagawa M, Chiba T. Nongated fetal MRI of umbilical blood flow in an Acardiac twin. Pediatric Radiology 2005; 35: 826-829. 

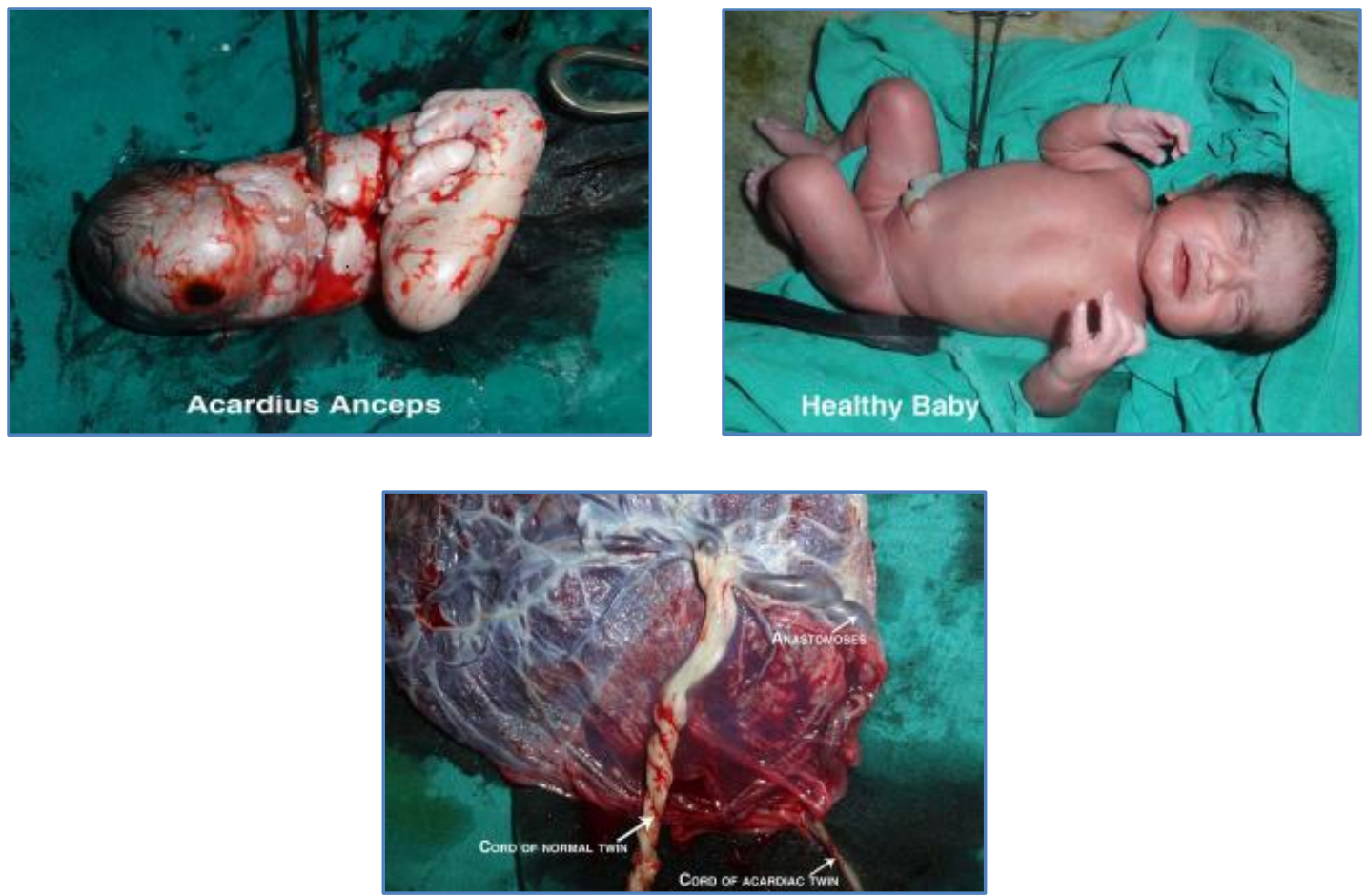

\section{AUTHORS:}

1. Padma Shukla

2. Neetu Ahirwar

3. Pooja Namdeo

\section{PARTICULARS OF CONTRIBUTORS:}

1. Assistant Professor, Department of Obstetrics and Gynaecology, S. S. Medical College \& GMH, Rewa, M. P.

2. Assistant Professor, Department of Obstetrics and Gynaecology, S. S. Medical College \& GMH, Rewa, M. P.

3. Post Graduate, Department of Obstetrics and Gynaecology, S. S. Medical College \& GMH, Rewa, M. P.

\section{NAME ADDRESS EMAIL ID OF THE CORRESPONDING AUTHOR:}

Dr. Padma Shukla,

12/145, Swapnil Khutchi,

Rewa, Madhya Pradesh.

E-mail: shukladrpadma@gmail.com

Date of Submission: 03/02/2014. Date of Peer Review: 04/02/2014. Date of Acceptance: 14/02/2014.

Date of Publishing: 25/02/2014. 